Check for updates

Cite this: RSC Adv., 2017, 7, 29428

Received 2nd May 2017

Accepted 31st May 2017

DOI: 10.1039/c7ra04916a

rsc.li/rsc-advances

\section{High-temperature solid-state reaction induced structure modifications and associated photoactivity and gas-sensing performance of binary oxide one-dimensional composite system}

\begin{abstract}
Yuan-Chang Liang (D) * and Ya-Ju Lo
The effects of high-temperature solid-state reactions on the microstructures, optical properties, photoactivity, and low-concentration $\mathrm{NO}_{2}$ gas-sensing sensitivity of $\mathrm{ZnO}-\mathrm{SnO}_{2}$ core-shell nanorods were investigated. In this study, the $\mathrm{ZnO}-\mathrm{SnO}_{2}$ core-shell nanorods were synthesized through a combination of the hydrothermal method and vacuum sputtering. According to X-ray diffraction and transmission electron microscopy analyses, high-temperature solid-state reactions between the $\mathrm{SnO}_{2}$ shell and $\mathrm{ZnO}$ core materials at $900{ }^{\circ} \mathrm{C}$ engendered an ultrathin $\mathrm{SnO}_{2}$ shell layer for transforming into the ternary $\mathrm{Zn}_{2} \mathrm{SnO}_{4}$ (ZTO) phase. Moreover, surface roughening was involved in the high-temperature solidstate reactions, as determined from electron microscopy images. Comparatively, the ZnO-ZTO nanorods have a higher oxygen vacancy density near the nanostructure surfaces than do the $\mathrm{ZnO}-\mathrm{SnO}_{2}$ nanorods. The photodegradation of rhodamine $\mathrm{B}$ dyes under simulated solar light irradiation in presence of the $\mathrm{ZnO}-\mathrm{SnO}_{2}$ and $\mathrm{ZnO}-\mathrm{ZTO}$ nanorods revealed that the $\mathrm{ZnO}-\mathrm{ZTO}$ nanorods have a higher photocatalytic activity than do the $\mathrm{ZnO}-\mathrm{SnO}_{2}$ nanorods. Furthermore, the $\mathrm{ZnO}-\mathrm{ZTO}$ nanorods exhibited higher gassensing sensitivity than did the $\mathrm{ZnO}-\mathrm{SnO}_{2}$ nanorods on exposure to low-concentration $\mathrm{NO}_{2}$ gases. The substantial differences in the microstructure and optical properties between the $\mathrm{ZnO}-\mathrm{SnO}_{2}$ and $\mathrm{ZnO}-$ ZTO nanorods accounted for the photocatalytic activity and $\mathrm{NO}_{2}$ gas-sensing results obtained in this study.
\end{abstract}

\section{Introduction}

The synthesis of low-dimensional metal oxide composites is a promising approach for designing oxide materials with improved functionalities. Several studies have demonstrated that low-dimensional metal oxide composites have superior photocatalytic activity and gas-sensing performance compared with single-constituent compounds. The photocatalytic activity and gas-sensing sensitivity of metal oxide composites are closely related to their different chemical components, architectures, and microstructures. Various material systems such as $\mathrm{Ag}_{2} \mathrm{O}$-decorated flower-like $\mathrm{ZnO}$ composites, $\mathrm{TiO}_{2}-\mathrm{WO}_{x}$ composite tubes, $\mathrm{ZnO}-\mathrm{ZnFe}_{2} \mathrm{O}_{4}$ composite nanorods, onedimensional (1D) $\mathrm{SnO}_{2}-\mathrm{CeO}_{2}$ composites, and $\mathrm{ZnO}-\mathrm{In}_{2} \mathrm{O}_{3}$ composite nanorods have been successfully synthesized, and studies have demonstrated that improved photocatalytic activity or gas-sensing sensitivity are highly correlated with the formation of heterojunctions and the resultant microstructural changes in the construction of low-dimensional composites. ${ }^{\mathbf{1 - 5}}$

Among various low-dimensional oxide composites, 1D coreshell oxide composites are one of the most promising

Institute of Materials Engineering, National Taiwan Ocean University, Keelung 20224, Taiwan.E-mail: yuanvictory@gmail.com heterostructure types that are applied to photocatalysts and gassensing fields, with enhanced properties in comparison with their constituent compounds. In general, a formation of lowdimensional oxide composites with satisfactory photocatalytic activity and gas-sensing properties should consider factors related to synthesis methodology and microstructure change. Most 1D oxide composites have been developed through a two-step technique, which might involve a combination of two chemical synthesis methods, either chemical and physical synthesis methods or two physical methods. The chemical durability and stability of the constituent compounds during the various synthesis methods are important for synthesizing various desired 1D composites. The hydrothermal method is promising for facile synthesis of various $1 \mathrm{D}$ oxides with a large-area coverage on different types of substrates, easy tailoring of morphology, and easy process parameter control; the hydrothermally derived 1D oxides are useful as templates for growing other oxide materials onto their surfaces to form a core-shell structure. ${ }^{6}$ Subsequently, the formation of a shell layer occurs through the deposition of an ultrathin layer (tens of nanometer) onto the surfaces of the host material structure. Chemical solution process-related methods, such as sol-gel and dip-coating methods, limit the control of the shell layer thickness, and a subsequent thermal process is usually needed to crystallize the shell layer. By contrast, a sputtering 
technique allows for any desired shell thickness to be applied simply by controlling the deposition duration, and crystalline shell oxides with controllable microstructures can be obtained through in situ crystal growth at various growing temperatures. ${ }^{7}$ Because of the different chemical natures of the constituent components, synthesizing the 1D core-shell composites through a combination of hydrothermal and physical synthesis methods is advantageous. ${ }^{5}$ This synthesis methodology prohibits possible deterioration of the host material crystallite feature during the second step of the chemical solution synthesis process for the shell layer.

Regarding the photocatalytic activity, the surface microstructures of 1D core-shell composites are important to the overall charge collection efficiency, because they can influence the photoexcited charge recombination and the chemical reaction dynamics. ${ }^{8}$ Furthermore, the gas-sensing sensitivity of $1 \mathrm{D}$ coreshell composites is also significantly affected by the surface structure of the shell layer. The heterojunction created at the interface of 1D core-shell composites plays an important role in enhancing the photocatalytic activity and gas-sensing properties when the shell layer thickness is down to tens of nanometers., ${ }^{9,10}$ Therefore, understanding the modifications in the surface microstructure-dependent photocatalytic activity and gas-sensing properties of 1D oxide core-shell composites is important for designing such composites with satisfactory performances. $\mathrm{SnO}_{2}$ and $\mathrm{ZnO}$ are two of the most important metal oxides and are widely used in photocatalysts and gas-sensing materials. ${ }^{11,12}$ Recent research and enhancement have led to the development of the ternary compound $\mathrm{Zn}_{2} \mathrm{SnO}_{4}$ (ZTO), which is based on an integrated composition of $\mathrm{ZnO}$ and $\mathrm{SnO}_{2}$. This ternary semiconductor compound is a promising material for application in photocatalysts and gas sensors. ${ }^{13,14}$ Due to the similar band alignment feature of the $\mathrm{ZnO}-\mathrm{SnO}_{2}$ and $\mathrm{ZnO}-\mathrm{ZTO}$ heterostructures ${ }^{15,16}$ these two types of heterostructures are suitable targets for investigating and understanding the physical mechanisms of shell-layer microstructural modifications in the photocatalytic activity and gas-sensing sensitivity of 1D core-shell composites.

In the present study, hydrothermally derived $1 \mathrm{D} \mathrm{ZnO}$ nanorods were sputtering coated with an ultrathin $\mathrm{SnO}_{2}$ layer to form

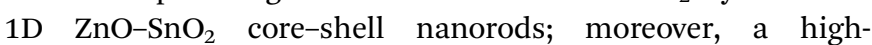
temperature postannealing procedure was conducted to induce a high-temperature solid-state reaction between the $\mathrm{ZnO}$ core and $\mathrm{SnO}_{2}$ shell, resulting in the formation of ZnO-ZTO coresell nanorods. The effects of microstructural and phase modifications on the photocatalytic activity and low-concentration $\mathrm{NO}_{2}$ gas-sensing sensitivity of the ZnO-based composite nanorods were investigated and discussed in this study.

\section{Experiments}

In this study, ZnO-based core-shell composite nanorods with the $\mathrm{SnO}_{2}$ and $\mathrm{Zn}_{2} \mathrm{SnO}_{4}$ (ZTO) shell layers $\left(\mathrm{ZnO}-\mathrm{SnO}_{2}\right.$ and $\mathrm{ZnO}-$ ZTO nanorods) were synthesized through a combinational methodology of hydrothermal and sputtering. Hydrothermally synthesized high-density $\mathrm{ZnO}$ nanorods were used as templates for growing the $\mathrm{ZnO}-\mathrm{SnO}_{2}$ and $\mathrm{ZnO}-\mathrm{ZTO}$ composite rods. The hydrothermal growth reactions of the $\mathrm{ZnO}$ rods were conducted at $95^{\circ} \mathrm{C}$ for 9 hours. The detailed preparation procedures for the hydrothermal growth of the $\mathrm{ZnO}$ nanorods have been reported elsewhere. ${ }^{17}$ During growth of the $\mathrm{SnO}_{2}$ shell layers onto the surfaces of the ZnO rods, the DC sputtering power of Sn metallic target was fixed at $30 \mathrm{~W}$. The thin-film growth temperature was maintained at $325{ }^{\circ} \mathrm{C}$ with an $\mathrm{Ar} / \mathrm{O}_{2}$ ratio of $25: 15$. The gas pressure during sputtering thin-film deposition was fixed at 2.67 Pa. For preparation of $\mathrm{ZnO}-\mathrm{ZTO}$ composite nanorods, the as-synthesized $\mathrm{ZnO}-\mathrm{SnO}_{2}$ core-shell nanorods were subsequently annealed in ambient air for 1 hour at the high temperature of $900{ }^{\circ} \mathrm{C}$ to induce a high-temperature solid-state reaction between the $\mathrm{ZnO}$ core and $\mathrm{SnO}_{2}$ shell and formed the ZnO-ZTO core-sell nanorods.

The surface morphology of the nanorod samples was investigated by scanning electron microscopy (SEM; Hitachi S-4800). Sample crystal structures were investigated by X-ray diffraction (XRD; Bruker D2 PHASER) using $\mathrm{Cu} \mathrm{K} \alpha$ radiation. The microstructures of the rod samples were characterized by highresolution transmission electron microscopy (HRTEM; Philips Tecnai F20 G2). X-ray photoelectron spectroscope (XPS; PHI 5000 VersaProbe) analysis was performed to determine the chemical binding states of the constituent elements of the nanostructures. The optical absorption spectra of the samples were recorded in the wavelength range of $300-800 \mathrm{~nm}$ by using UV-Vis spectrophotometer (Jasco V750). Room temperature dependent photoluminescence (PL; Horiba HR800) spectra were obtained using the $325 \mathrm{~nm}$ line of a He-Cd laser. Photocatalytic activity of various nanorod samples were performed by comparing the degradation of aqueous solution of rhodamine B (RhB; $\left.10^{-6} \mathrm{M}\right)$ containing various nanorod samples as catalysts under solar light irradiation excited from a $100 \mathrm{~W}$ Xe arc lamp. The solution volume of $\mathrm{RhB}$ is $10 \mathrm{ml}$ and the nanorods are grown on the 300 $\mathrm{nm}$-thick $\mathrm{SiO}_{2} / \mathrm{Si}$ substrates with a fixed coverage area of $1.0 \mathrm{~cm}$ $\times 1.0 \mathrm{~cm}$ for photodegradation tests. The variation of $\mathrm{RhB}$ solution concentration in presence of various nanorod samples with different irradiation durations was analyzed by recording the absorbance spectra using an UV-Vis spectrophotometer. Silver glues were laid on the surfaces of the nanorods to form two contact electrodes for gas-sensing measurements. To measure oxidizing gas sensing properties, sensors were placed in a closed vacuum chamber and various concentrations $(1.0,2.5,5.0,7.5$ and $10.0 \mathrm{ppm}$ ) of $\mathrm{NO}_{2}$ gas were introduced into the chamber, using dry $\mathrm{N}_{2}$ as the carrier gas. All the sensing properties of the sensors were measured at $300{ }^{\circ} \mathrm{C}$. The gas sensing response of the sensors to $\mathrm{NO}_{2}$ gas is defined as the $R_{\mathrm{g}} / R_{\mathrm{a}} . R_{\mathrm{a}}$ is the electrical resistance of the sensor in the absence of target gas and $R_{\mathrm{g}}$ is the electrical resistance of the sensor in target gas. The response time is defined as the durations required to reach $90 \%$ variation in sensor resistance upon exposure to $\mathrm{NO}_{2}$ and the recovery time is the durations required to reach $90 \%$ variation in sensor resistance on removal of $\mathrm{NO}_{2}$ gas. ${ }^{12}$

\section{Results and discussion}

Fig. 1(a) shows the top view of a SEM image of the assynthesized $\mathrm{ZnO}$ nanorods. The cross-section of the $\mathrm{ZnO}$ nanorods has a hexagonal crystal feature. The SEM image of the 


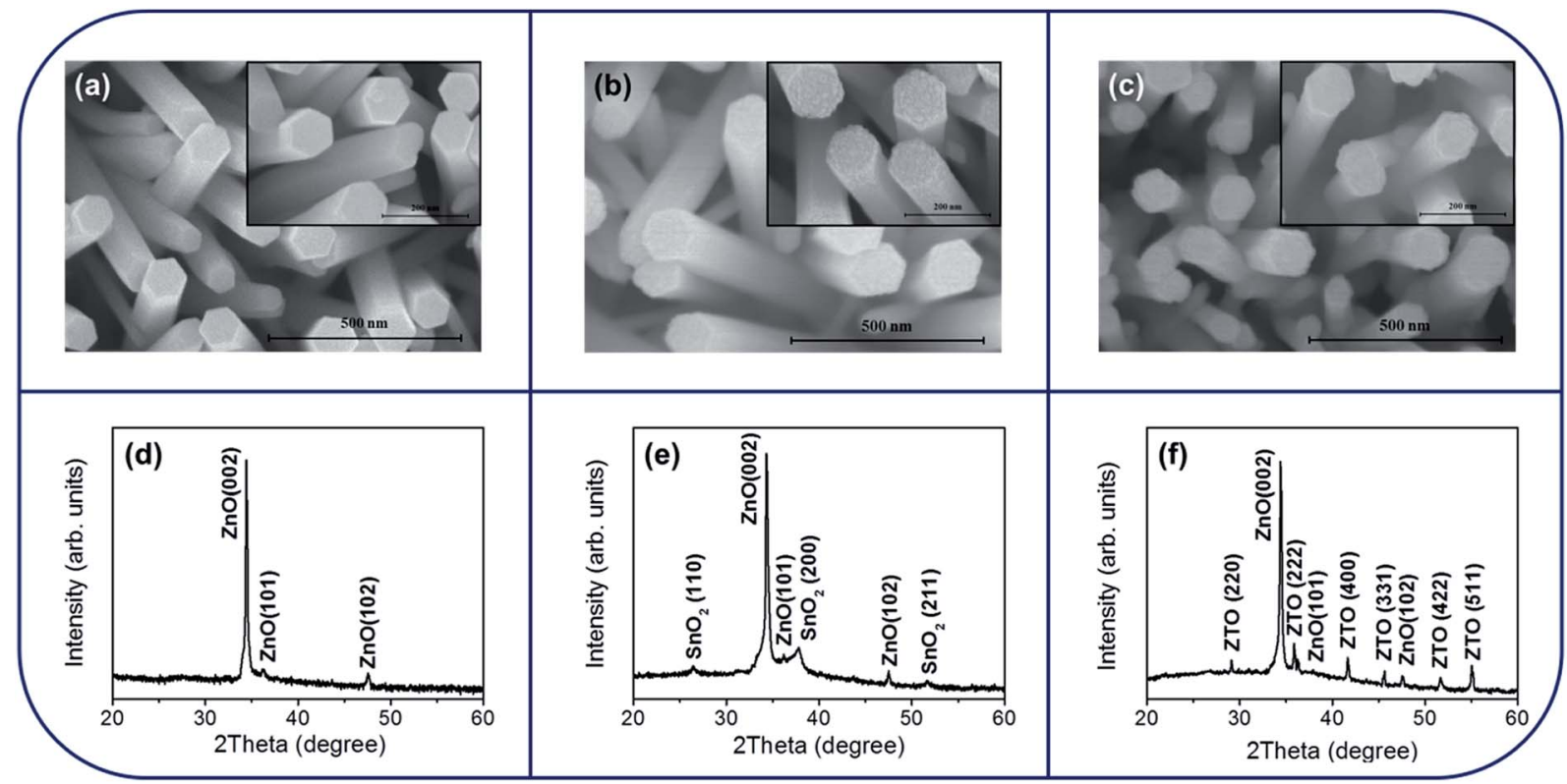

Fig. 1 SEM images of various nanorod samples: (a) $\mathrm{ZnO}$. (b) $\mathrm{ZnO}-\mathrm{SnO}_{2}$. (c) $\mathrm{ZnO}-\mathrm{ZTO}$. XRD patterns of various nanorod samples: (d) $\mathrm{ZnO}$. (e) $\mathrm{ZnO}-\mathrm{SnO}_{2}$. (f) $\mathrm{ZnO}-\mathrm{ZTO}$.

$\mathrm{ZnO}$ nanorods that were sputtering coated with the $\mathrm{SnO}_{2}$ shell layer is exhibited in Fig. 1(b). Tiny granular crystallites were observed to cover the surfaces of the $\mathrm{ZnO}$ nanorods after encapsulating the $\mathrm{SnO}_{2}$ layer through sputtering. The surface became more rugged than that of the $\mathrm{ZnO}$ nanorods. The favorable free-standing and rod-like crystal feature of the $\mathrm{ZnO}$ was maintained after the thin-film deposition of the $\mathrm{SnO}_{2}$ thin

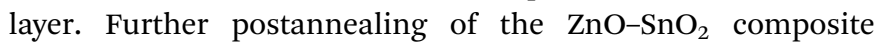
nanorods at a high temperature engendered the surface roughening of the composite nanorods (Fig. 1(c)). The surface crystallite size became large when the $\mathrm{ZnO}-\mathrm{SnO}_{2}$ composite nanorods were postannealed at a high temperature. This might be associated with the possible phase transformation or crystal growth of the surface grains during the high-temperature solidstate reaction..$^{18}$ A similar phenomenon, wherein hightemperature annealing causes the surfaces of the core-shell oxide nanostructures to become irregular and rough, has been observed in the $\mathrm{ZnO}-\mathrm{TiO}_{2}$ and $\mathrm{Ga}_{2} \mathrm{O}_{3}-\mathrm{ZnO}$ core-shell nanostructures annealed at a high temperature of $800{ }^{\circ} \mathrm{C} \cdot{ }^{19,20}$ Fig. 1(d)-(f) show the XRD patterns of the as-synthesized $\mathrm{ZnO}$ nanorods, $\mathrm{ZnO}-\mathrm{SnO}_{2}$ nanorods, and $\mathrm{ZnO}-\mathrm{SnO}_{2}$ nanorods annealed at $900{ }^{\circ} \mathrm{C}$. In Fig. 1(d), all the diffraction peaks can be indexed to hexagonal wurtzite structure of ZnO (JCPDS no. 0050664). The XRD pattern demonstrated a strong Bragg reflection of $\mathrm{ZnO}$ (200), revealing that most $\mathrm{ZnO}$ nanorod crystals are highly $c$-axis-oriented. In Fig. 1(e), in addition to the Bragg reflections originated from $\mathrm{ZnO}$, three distinct Bragg reflections located at approximately $26.58^{\circ}, 37.95^{\circ}$ and $51.75^{\circ}$ were observed, which can be assigned to the (110), (200), and (211) planes of tetragonal $\mathrm{SnO}_{2}$ (JCPDS no. 021-1250), respectively. The XRD pattern revealed that a well formation of the crystalline $\mathrm{ZnO}_{-} \mathrm{SnO}_{2}$ composite nanorods when the $\mathrm{ZnO}$ nanorod template was sputtering coated with the $\mathrm{SnO}_{2}$ thin film. Fig. 1(f) shows the XRD pattern of the as-synthesized $\mathrm{ZnO}-\mathrm{SnO}_{2}$ nanorods annealed at $900{ }^{\circ} \mathrm{C}$. In addition to the Bragg reflections from the remaining $\mathrm{ZnO}$ core, the Bragg reflections in the XRD patterns are associated with the cubic ternary ZTO phase (JCPDS no. 024-1470). Moreover, the Bragg reflections of the $\mathrm{SnO}_{2}$ phase were absent in the XRD pattern, revealing that the $\mathrm{SnO}_{2}$ was fully transformed into the ZTO phase during the hightemperature solid-state reaction with the $\mathrm{ZnO}$ core. A successful formation of ternary $\mathrm{Zn}-\mathrm{Ti}-\mathrm{O}$ compound from the solidstate reaction of the constituent binary compounds in a onedimensional structure has been reported in $\mathrm{ZnO}^{-\mathrm{TiO}_{2}}$ system with a temperature higher than $800{ }^{\circ} \mathrm{C} .{ }^{18}$ Moreover, it has been shown that the solid-state reaction between $\mathrm{ZnO}$ and $\mathrm{SnO}_{2}$ generate a phase formation of the ternary ZTO when the annealing temperature is higher than $900^{\circ} \mathrm{C} .{ }^{21}$ The XRD results herein demonstrated that the annealing temperature of $900{ }^{\circ} \mathrm{C}$ in this study is enough to induce the solid-state reaction between the $\mathrm{ZnO}$ core and $\mathrm{SnO}_{2}$ shell of the composite nanorods and the formation of the ZTO shell layer on the residual $\mathrm{ZnO}$ core.

Fig. 2(a) shows a low-magnification TEM image of a single $\mathrm{ZnO}-\mathrm{SnO}_{2}$ core-shell nanorod. A thin $\mathrm{SnO}_{2}$ layer was homogeneously covered over the surface of the $\mathrm{ZnO}$ nanorod. The thickness of the $\mathrm{SnO}_{2}$ shell layer is approximately 15-20 nm. The surface crystallite size is in the range of approximately 4$6 \mathrm{~nm}$. The surface of the $\mathrm{SnO}_{2}$ shell layer exhibited a tiny groove surface feature. Fig. 2(b)-(d) show the HRTEM images of the $\mathrm{ZnO}-\mathrm{SnO}_{2}$ core-shell nanorod taken from the different local regions at the $\mathrm{ZnO} / \mathrm{SnO}_{2}$ interface. From the HRTEM images, the variation size of the surface undulation from the convex to concave portions of the $\mathrm{SnO}_{2}$ layer is approximately 2-3 nm. The clear lattice fringes in the HRTEM images with an interplanar spacing of approximately $0.33 \mathrm{~nm}$ and $0.23 \mathrm{~nm}$ corresponded to 


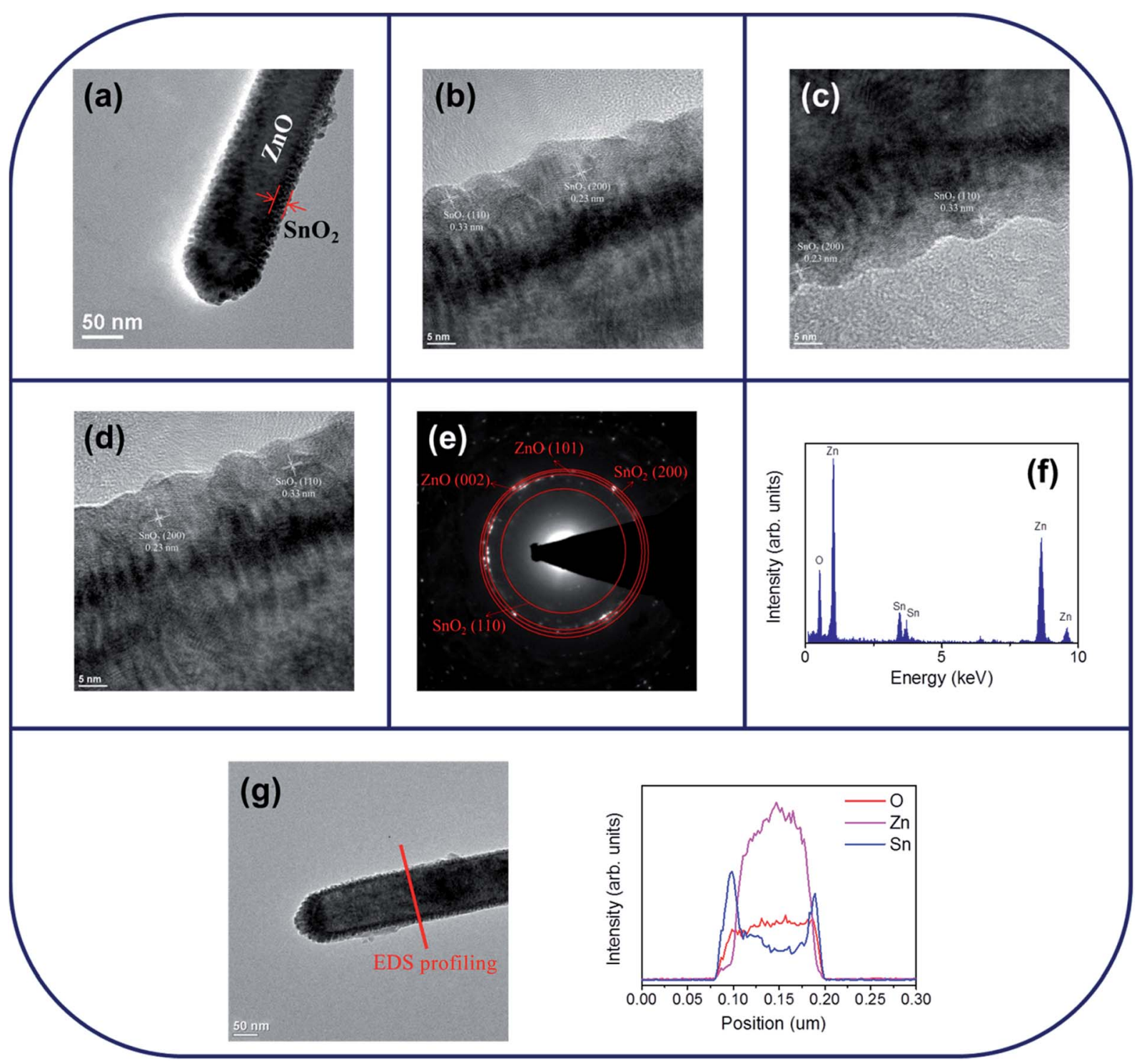

Fig. 2 TEM analyses of $\mathrm{ZnO}-\mathrm{SnO}_{2}$ nanorod: (a) low-magnification TEM image of the nanorod. (b)-(d) HRTEM images taken from the local regions of the nanorod. (e) SAED pattern taken from the multiple $\mathrm{ZnO}-\mathrm{SnO}_{2}$ nanorods. (f) EDS spectra of $\mathrm{Zn}$, Sn, and O elements taken from the nanorod. (g) EDS line-scan profiling spectra across the nanorod.

the $\{110\}$ and $\{200\}$ lattice plane of the tetragonal $\mathrm{SnO}_{2}$ structure, respectively. The selected area electron diffraction (SAED) pattern was taken from the multiple composite nanorods in order to obtain the sufficient signals from the ultrathin shell layer and to identify the phase structure of the composite nanorods. Fig. 2(e) depicted a formation of the $\mathrm{ZnO}-\mathrm{SnO}_{2}$ heterostructure, which exhibited rings consisted of the sharp, bright spots from the $\mathrm{ZnO}$ core and the ultrathin $\mathrm{SnO}_{2}$ shell layer. The energy-dispersive X-ray spectroscopy (EDS) spectra displayed in Fig. 2(f) show that $\mathrm{Zn}$, Sn and $\mathrm{O}$ are the main constituent elements of the selected composite nanorod. The local composition distribution of the $\mathrm{ZnO}^{-\mathrm{SnO}_{2}}$ composite nanorod was investigated using EDS spectra by line scanning across the nanorod (Fig. 2(g)). The intensity profiles of $\mathrm{Zn}$ and Sn across to the nanorod exhibited a sharp Sn compositional distribution in the peripheral region of the composite nanorod and a high $\mathrm{Zn}$ compositional distribution in the inner region of the composite nanorod. Fig. 3(a) shows a low-magnification TEM image of a single ZnO-ZTO core-shell nanorod. Comparatively, the surface crystallite size of the ZnO-ZTO nanorod is larger than that of the $\mathrm{ZnO}-\mathrm{SnO}_{2}$ nanorod and has a size range of approximately 14-20 $\mathrm{nm}$. The ZnO-ZTO nanorod surface exhibited a distinct rugged surface feature; the surface is rougher than that of the $\mathrm{ZnO}-\mathrm{SnO}_{2}$ nanorod. Fig. 3(b)-(d) display the HRTEM images of various interfacial regions of the ZnO-ZTO nanorod. The images clearly show that the surface morphology of the shell layer exhibited an irregular grainy feature. The boundaries between the adjacent ZTO crystallites in the shell layer are clear. The ordered lattice fringes with an interval of approximately $0.30 \mathrm{~nm}$ and $0.24 \mathrm{~nm}$ corresponded to the $\{220\}$ and $\{222\}$ lattice distance of the crystallographic planes of the cubic ZTO, respectively. Fig. 3(e) presents the 


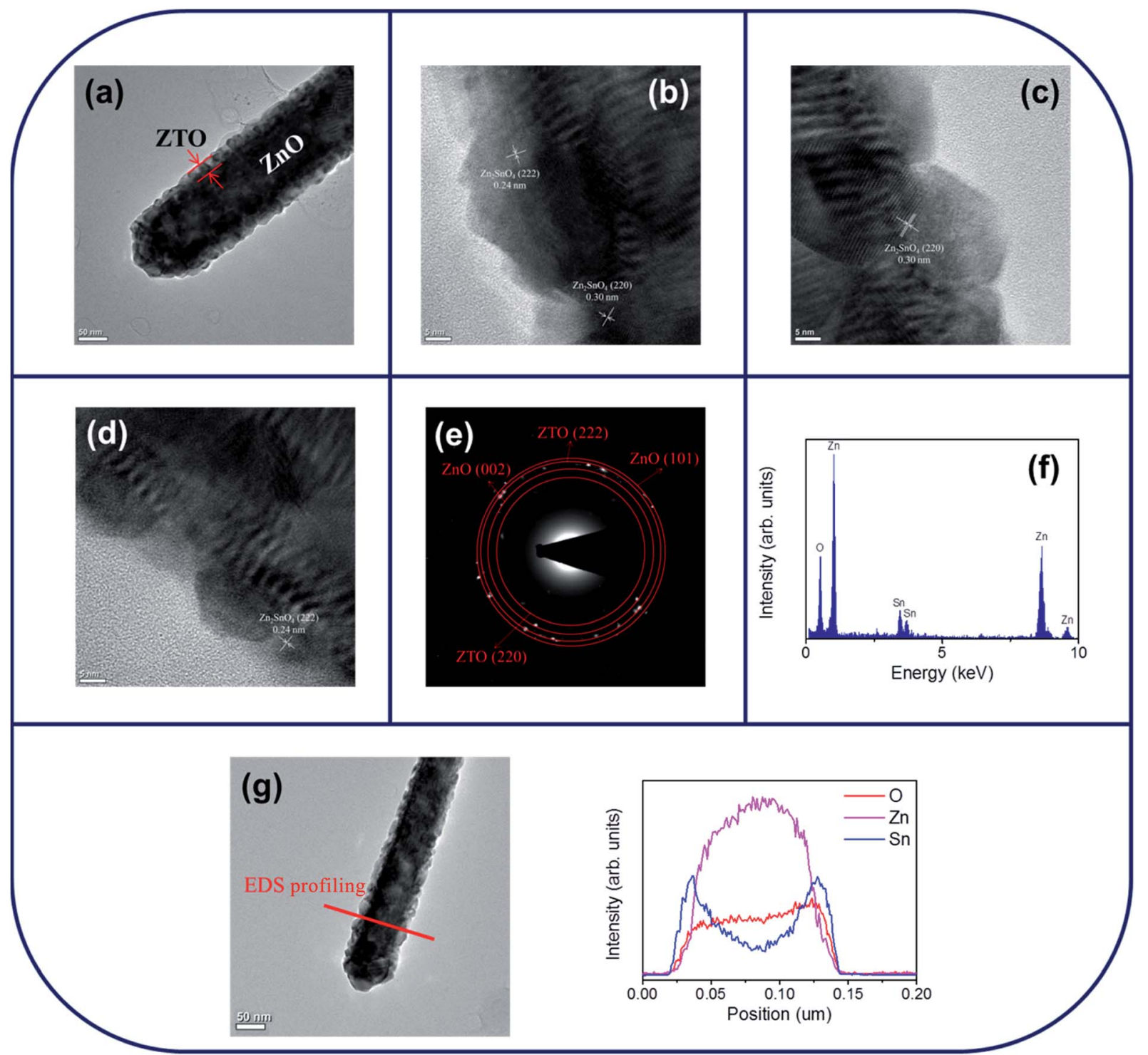

Fig. 3 TEM analyses of ZnO-ZTO nanorod: (a) low-magnification TEM image of the nanorod. (b)-(d) HRTEM images taken from the local regions of the nanorod. (e) SAED pattern taken from the multiple $\mathrm{ZnO}-\mathrm{ZTO}$ nanorods. (f) EDS spectra of $\mathrm{Zn}$, Sn, and O elements taken from the nanorod. (g) EDS line-scan profiling spectra across the nanorod.

SAED pattern of multiple composite nanorods. Ring patterns consisted of crystallographic planes originated from two different phases of $\mathrm{ZnO}$ and ZTO were observed; moreover, no electron diffraction signal contribution from the $\mathrm{SnO}_{2}$ phase was observed, revealing a well formation of the crystalline $\mathrm{ZnO}-$ ZTO heterostructure. The TEM structural analysis revealed that the ultrathin $\mathrm{SnO}_{2}$ shell layer was fully transformed into ZTO phase during the high-temperature solid-state reaction with $\mathrm{ZnO}$ core material in this study. The elemental composition of the selected composite rod was evaluated to be $\mathrm{Zn}, \mathrm{Sn}$ and $\mathrm{O}$ elements from the EDS spectra in Fig. 3(f). Line-scan profiles of $\mathrm{Zn}$, Sn, and O elements across the ZnO-ZTO composite nanorod (Fig. 3(g)) clearly show that a well ZTO shell layer homogeneously covered on the $\mathrm{ZnO}$ core.

Fig. 4(a)-(c) show the XPS narrow scan spectra in the Zn 2p region of the $\mathrm{ZnO}, \mathrm{ZnO}-\mathrm{SnO}_{2}$, and $\mathrm{ZnO}-\mathrm{ZTO}$ nanorods. The peaks of $\mathrm{Zn} 2 \mathrm{p}_{3 / 2}$ for the $\mathrm{ZnO}, \mathrm{ZnO}-\mathrm{SnO}_{2}$, and $\mathrm{ZnO}-\mathrm{ZTO}$ nanorods were centered at 1021.7-1022.2 eV; the peaks of $\mathrm{Zn}$ $2 \mathrm{p}_{1 / 2}$ were located at 1044.8-1045.2 eV. The binding energies of the $\mathrm{Zn} 2 \mathrm{p}$ have been ascribed to the binding state of $\mathrm{Zn}^{2+}$ in the ZnO. ${ }^{15,22,23}$ Fig. 4(d) and (e) show that the symmetric peaks originated from the Sn 3d core-level doublet. The binding energy differences between the $S n 3 d_{3 / 2}$ and $S n 3 d_{5 / 2}$ peaks for the $\mathrm{ZnO}-\mathrm{SnO}_{2}$ and $\mathrm{ZnO}-\mathrm{ZTO}$ composite nanorods were similar (approximately $8.4 \mathrm{eV}$ ), revealing the $\mathrm{Sn}^{4+}$ binding status in the oxides. ${ }^{12,24}$ No signal from the metallic Sn was observed in the samples, indicating that sputtering deposited the $\mathrm{SnO}_{2}$ thin film, and further postannealing of the $\mathrm{ZnO}-\mathrm{SnO}_{2}$ nanorods maintained the $\mathrm{Sn}^{4+}$ in the oxide lattices. Fig. 5(a)-(c) show that the XPS spectra of $\mathrm{O}$ 1s for the $\mathrm{ZnO}, \mathrm{ZnO}-\mathrm{SnO}_{2}$, and $\mathrm{ZnO}-\mathrm{ZTO}$ nanorods have an asymmetric curve feature. Two Gaussian curves fitted the $\mathrm{O}$ 1s peak. The relatively low binding energy 

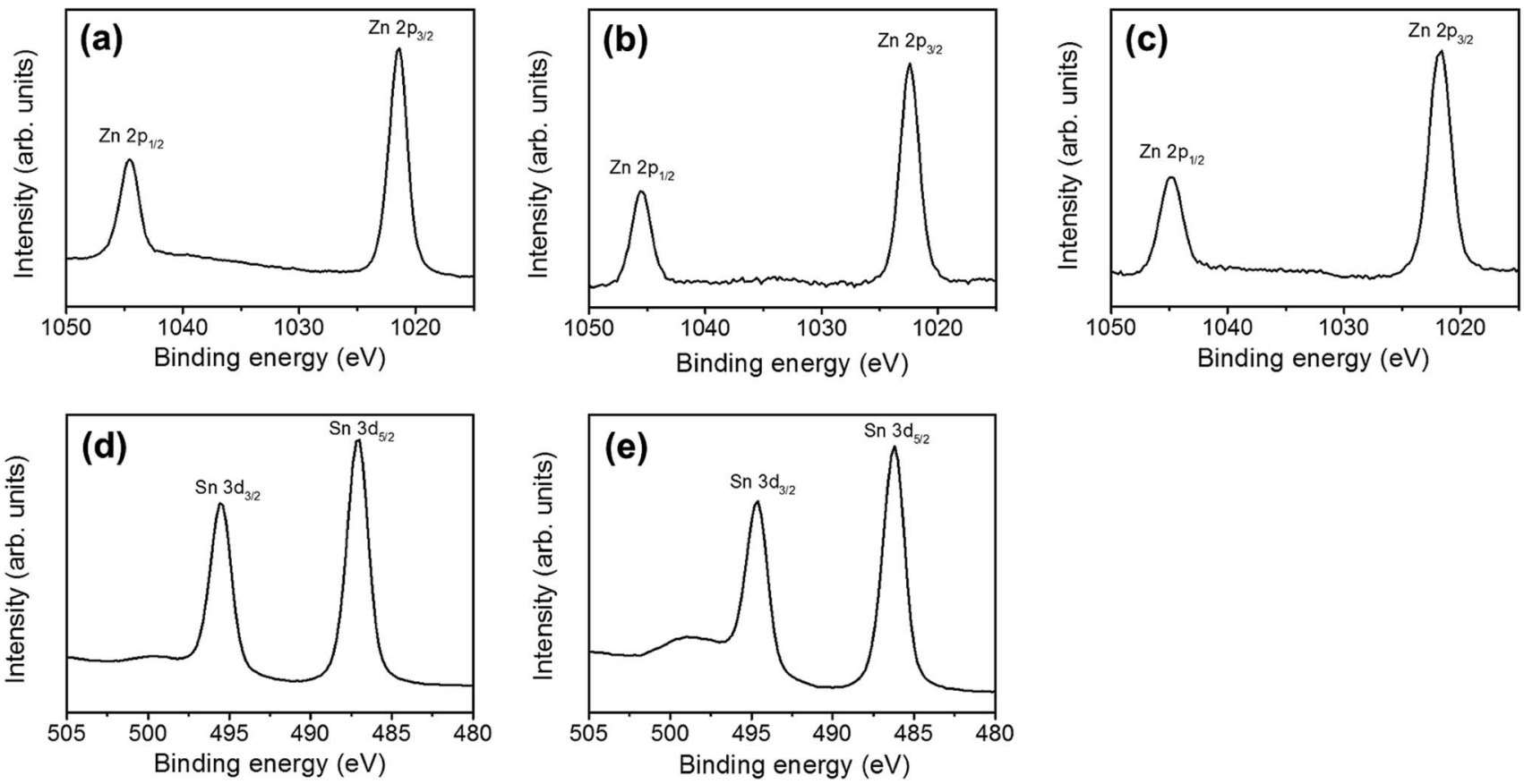

Fig. 4 XPS narrow scans of $\mathrm{Zn} 2 \mathrm{p}$ region of various nanorod samples: (a) $\mathrm{ZnO}$. (b) $\mathrm{ZnO}-\mathrm{SnO}_{2}$. (c) $\mathrm{ZnO}-\mathrm{ZTO}$. XPS narrow scans of Sn $3 \mathrm{~d}$ core level doublet of various nanorod samples: (d) $\mathrm{ZnO}-\mathrm{SnO}_{2}$. (e) $\mathrm{ZnO}-\mathrm{ZTO}$.

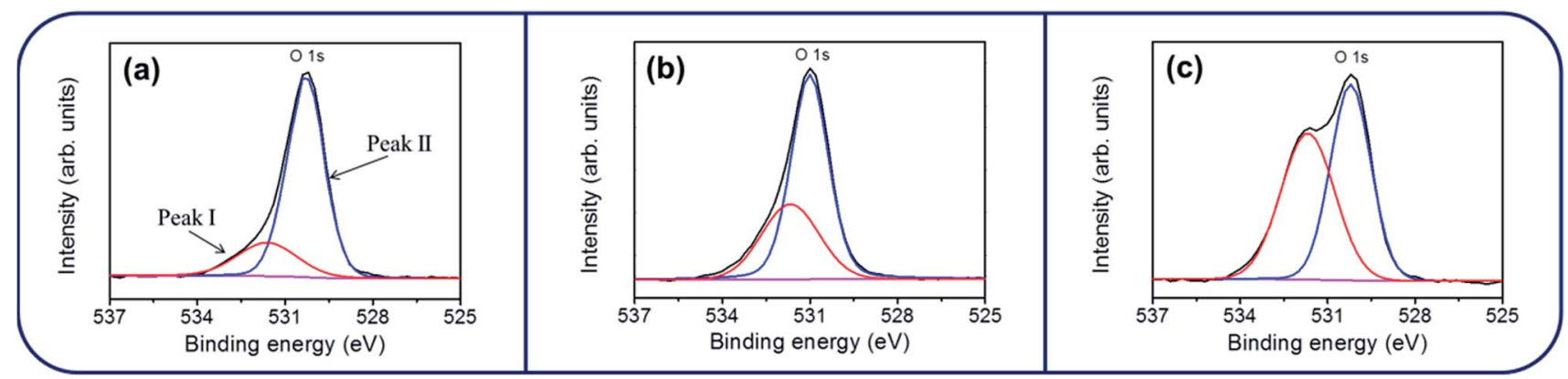

Fig. 5 XPS narrow scans of $\mathrm{O} 1 \mathrm{~s}$ core level of various nanorod samples: (a) $\mathrm{ZnO}$. (b) $\mathrm{ZnO}-\mathrm{SnO}$. (c) $\mathrm{ZnO}-\mathrm{ZTO}$.

component located at approximately $530.1-530.5 \mathrm{eV}$ is associated with the crystal lattice oxygen in the oxide. The high binding energy component located at approximately 531.4$531.9 \mathrm{eV}$ is attributed to the presence of oxygen vacancies within the oxide matrix. ${ }^{25}$ The peak intensity at the higher binding energy slightly increased when the ZnO nanorods were decorated with the $\mathrm{SnO}_{2}$ shell layer using sputtering. Moreover, the peak intensity at the higher binding energy substantially increased in the ZnO-ZTO nanorods. The relative oxygen vacancy content of the $\mathrm{ZnO}, \mathrm{ZnO}-\mathrm{SnO}_{2}$, and $\mathrm{ZnO}-\mathrm{ZTO}$ nanorods was evaluated according to the following intensity ratio of these two Gaussian deconvolution peaks: (red peak)/(red peak + blue peak). ${ }^{26}$ The relative ratios of oxygen vacancy in the $\mathrm{ZnO}, \mathrm{ZnO}-$ $\mathrm{SnO}_{2}$, and $\mathrm{ZnO}-\mathrm{ZTO}$ nanorods were approximately $31 \%$, 37\%, and $46 \%$, respectively. The formation of oxygen vacancy in the ZnO nanorods is generally attributed to the high aspect ratio of oxide nanostructures, which easily form oxygen vacancies in the lattices during crystal growth in the low-temperature reaction. ${ }^{27}$
The slight increase in the oxygen vacancy content of the $\mathrm{ZnO}-$ $\mathrm{SnO}_{2}$ nanorods is associated with the fact that the $\mathrm{SnO}_{2}$ thin film was sputtering coated under an oxygen-deficient ambient; this usually causes the formation of oxygen vacancies in the sputtering-deposited oxide thin films. ${ }^{28}$ Accordingly, the oxygen vacancy content of the composite nanorods substantially increased during the high-temperature solid-state reaction of the $\mathrm{ZnO}-\mathrm{SnO}_{2}$ nanorods. The $\mathrm{O}$ 1s XPS results revealed that a relatively high degree of oxygen vacancy density was formed in the surfaces of the ZnO-ZTO nanorods.

Fig. 6(a) shows the UV-Vis absorbance spectra of the $\mathrm{ZnO}$, $\mathrm{ZnO}-\mathrm{SnO}_{2}$, and $\mathrm{ZnO}-\mathrm{ZTO}$ nanorods. By comparison, a clear redshift was observed for the $\mathrm{ZnO}$ nanorods coated with the $\mathrm{SnO}_{2}$ shell layer. Moreover, the $\mathrm{ZnO}-\mathrm{ZTO}$ nanorods had a larger redshift in comparison with the $\mathrm{ZnO}-\mathrm{SnO}_{2}$ nanorods. These results shows that the optical bandgaps of the ZnO-based composite nanorods were narrower than that of the $\mathrm{ZnO}$ nanorods when the $\mathrm{SnO}_{2}$ and ZTO were covered onto the 


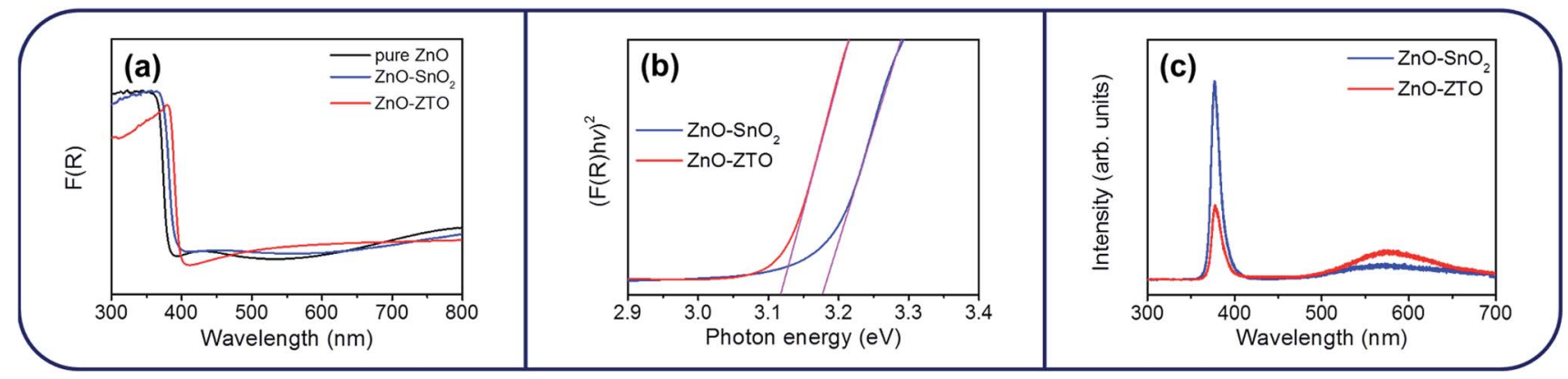

Fig. 6 (a) Optical absorbance spectra of various nanorod samples. (b) $(F(R) h v)^{2}$ vs. Photon energy plot. (c) $\mathrm{PL}$ spectra of $\mathrm{ZnO} \mathrm{SnO} \mathrm{O}_{2}$ and $\mathrm{ZnO}-$ ZTO nanorods.

surfaces of the $\mathrm{ZnO}$ nanorods. The optical bandgaps of the $\mathrm{ZnO}-\mathrm{SnO}_{2}$ and $\mathrm{ZnO}-\mathrm{ZTO}$ nanorods were evaluated according to the formula $(F(R) h \nu)^{n}=C\left(h \nu-E_{\mathrm{g}}\right)$, where $F(R)$ is the linear absorption coefficient of the material, $h \nu$ is the photon energy, $C$ is a proportionality constant, and $E_{\mathrm{g}}$ is the bandgap. The exponent $n=2$ for direct bandgap semiconductors was used for the oxides herein. ${ }^{29,30}$ The estimated bandgap values of the $\mathrm{ZnO}-\mathrm{SnO}_{2}$ and $\mathrm{ZnO}-\mathrm{ZTO}$ nanorods are shown in Fig. 6(b). The optical bandgap values of the $\mathrm{ZnO}-\mathrm{SnO}_{2}$ and $\mathrm{ZnO}-\mathrm{ZTO}$ nanorods were approximately 3.17 and $3.11 \mathrm{eV}$, respectively. Previous studies have reported that a large concentration of oxygen vacancy can induce bandgap narrowing and optical absorbance edge redshift in oxide semiconductors. ${ }^{31,32}$ Moreover, the widebandgap $\mathrm{TiO}_{2}$ and $\mathrm{ZnO}$ oxides for forming heterostructures have been shown to engender a clear redshift. ${ }^{33}$ The composite effects of crystal defects and the shell layer on the $\mathrm{ZnO}$ core influenced the optical bandgap of the as-synthesized samples. The effect of high-temperature thermal annealing on the surface defect density of the $\mathrm{ZnO}-\mathrm{SnO}_{2}$ composite nanorods was further investigated through PL. Fig. 6(c) illustrates the PL

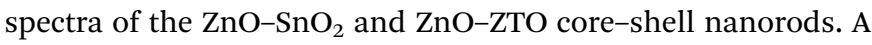
sharp and distinct UV emission band was ascribed to the nearband edge (NBE) emission of the ZnO nanorods. ${ }^{22,34}$ Moreover, a broad and clear visible-light emission band centered at approximately $570 \mathrm{~nm}$ was observed for the $\mathrm{ZnO}-\mathrm{SnO}_{2}$ and ZnO-ZTO nanorods. This visible emission band was associated with deep-level emissions, which were attributed to the existence of oxygen vacancies near the oxide surface. ${ }^{7}$ Notably, the NBE intensity of the ZnO-ZTO nanorods decreased significantly compared with that of the $\mathrm{ZnO}-\mathrm{SnO}_{2}$ nanorods; moreover, the intensity ratio of the visible emission band to the NBE band was substantially increased when the $\mathrm{ZnO}-\mathrm{SnO}_{2}$ nanorods were transformed into the ZnO-ZTO nanorods after hightemperature postannealing. A comparison of the PL spectra between the $\mathrm{ZnO}-\mathrm{SnO}_{2}$ and $\mathrm{ZnO}-\mathrm{ZTO}$ nanorods revealed that an increase in the number of surface crystal defects in the composite nanorods occurs in a high-temperature solid-state reaction. The PL results are consistent with the XPS and UVVis analyses, which all supported a higher crystal defect density in the $\mathrm{ZnO}-\mathrm{ZTO}$ composite nanorods than in the $\mathrm{ZnO}-$ $\mathrm{SnO}_{2}$ nanorods.

The photocatalytic activity of $\mathrm{ZnO}$ nanorods with various shell layer materials was compared through photocatalytic decomposition experiments involving RhB dyes. As depicted in Fig. 7(a)-(c), the main absorption peaks of the RhB solution at approximately $550 \mathrm{~nm}$ decreased gradually in the presence of the various nanorod photocatalysts under solar light irradiation, with different durations. At a given irradiation duration, the drop in absorbance intensity was more substantial for the $\mathrm{RhB}$ solution containing ZnO-ZTO nanorods than that for the solution containing bare- $\mathrm{ZnO}$ and $\mathrm{ZnO}-\mathrm{SnO}_{2}$ nanorods. The photodegradation degree of the RhB solution for the various nanorod samples was evaluated as $C / C_{\mathrm{o}}$, wherein $C$ is the concentration of $\mathrm{RhB}$ remaining in the solution after a given irradiation time, and $C_{\mathrm{o}}$ is the initial concentration of $\mathrm{RhB}$ without irradiation. The $C / C_{\mathrm{o}}$ versus irradiation duration results for various nanorod samples are shown in Fig. 7(d). Dark adsorption tests were performed for various durations before the photocatalytic degradation tests under irradiation. Notably, after $180 \mathrm{~min}$ in dark conditions, less than $5 \%$ of the RhB dyes were absorbed by the as-synthesized samples in this study. When the adsorption-desorption equilibrium was established, all samples were irradiated with solar light for various durations. From Fig. 7(d), the $C / C_{\mathrm{o}}$ values of the $\mathrm{ZnO}, \mathrm{ZnO}-\mathrm{SnO}_{2}$, and ZnO-ZTO nanorods after 180 min of solar light irradiation were approximately $0.52,0.36$, and 0.17 , respectively. The ZnOZTO nanorods exhibited a superior photodegradation performance compared with the $\mathrm{ZnO}$ and $\mathrm{ZnO}-\mathrm{SnO}_{2}$ nanorods. The inset figures show the corresponding times for the RhB solution containing $\mathrm{ZnO}-\mathrm{SnO}_{2}$ and $\mathrm{ZnO}$-ZTO nanorods with the photodegradation processes of various durations. Discolorations of the $\mathrm{RhB}$ solution containing the $\mathrm{ZnO}-\mathrm{SnO}_{2}$ and $\mathrm{ZnO}-\mathrm{ZTO}$ nanorods under solar light irradiation were visible. Moreover, the $\mathrm{RhB}$ solution containing ZnO-ZTO nanorods became almost translucent after $180 \mathrm{~min}$ of light irradiation. These observations revealed that the chromophoric structure of the $\mathrm{RhB}$ molecules was gradually decomposed during the photodegradation process. Notably, the construction of $\mathrm{ZnO}-\mathrm{SnO}_{2}$ and $\mathrm{ZnO}-\mathrm{ZTO}$ heterostructures enhanced the photodegradation efficiency of the $\mathrm{ZnO}$ nanorods. The enhanced photocatalytic ability of the $\mathrm{ZnO}$ nanorods toward the RhB dyes, achieved by incorporating $\mathrm{SnO}_{2}$ or the ZTO shell layer, could be detected from the band alignment of the $\mathrm{ZnO} / \mathrm{SnO}_{2}$ and $\mathrm{ZnO} / \mathrm{ZTO}$ (Fig. 8). ${ }^{15,16}$ Under light irradiation, the electrons $\left(\mathrm{e}^{-}\right)$in the valence band are excited to the conduction band, with simultaneous generation of the same amount of holes $\left(\mathrm{h}^{+}\right)$in the 


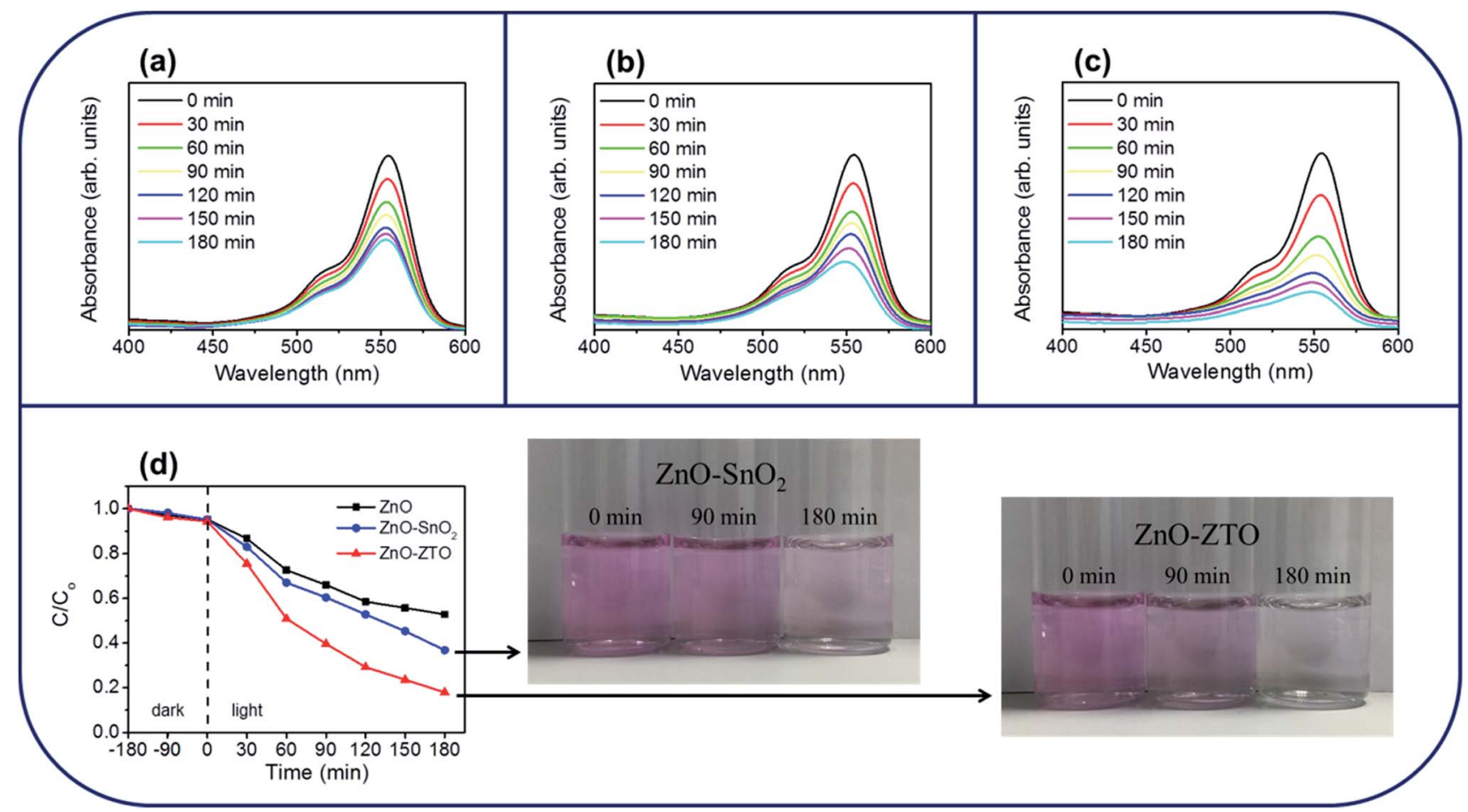

Fig. 7 Intensity variation of absorbance spectra of RhB solution vs. degradation duration containing various nanorod samples under solar light illumination: (a) pure $\mathrm{ZnO}$ nanorods. (b) $\mathrm{ZnO}-\mathrm{SnO}_{2}$ nanorods. (c) $\mathrm{ZnO}-\mathrm{ZTO}$ nanorods. (d) $\mathrm{C} / \mathrm{C}_{\mathrm{o}}$ vs. irradiation time curves for RhB solution containing various nanorod samples in dark conditions and under solar light illumination. The pictures of the $\mathrm{RhB}_{\text {solution containing } \mathrm{ZnO}-\mathrm{SnO}}$ and $\mathrm{ZnO}-\mathrm{ZTO}$ nanorods under solar light illumination at different durations are displayed for a comparison.

valance band. Because the conduction band of $\mathrm{SnO}_{2}$ (or ZTO) is lower than that of $\mathrm{ZnO}$, the photoexcited electrons will transfer from the conduction band of $\mathrm{ZnO}$ to that of $\mathrm{SnO}_{2}$ (or ZTO). Conversely, the holes transfer from the valance band of $\mathrm{SnO}_{2}$ (or ZTO) to that of $\mathrm{ZnO}^{35}$ The photogenerated electrons and holes in the as-synthesized nanorod photocatalysts could be injected into a reaction medium and made to participate in degradation reactions with the organic dyes. ${ }^{36}$ The adsorbed $\mathrm{O}_{2}$ on the shell surfaces of the composite nanorods in the RhB solution can trap the photogenerated electron to produce a superoxide anion radical $\left({ }^{\circ} \mathrm{O}_{2}^{-}\right)\left(\mathrm{e}^{-}+\mathrm{O}_{2} \rightarrow{ }^{\circ} \mathrm{O}_{2}{ }^{-}\right)$. The formed ${ }^{\circ} \mathrm{O}_{2}{ }^{-}$reacts with $\mathrm{e}^{-}$ and $\mathrm{H}^{+}$to produce $\mathrm{H}_{2} \mathrm{O}_{2}$, which provides a hydroxyl radical $\left({ }^{\circ} \mathrm{OH}\right)$ by acting as a direct electron acceptor through a reaction with $\mathrm{e}^{-}$and ${ }^{\circ} \mathrm{O}_{2}{ }^{-}$. Moreover, hydroxyl radicals $\left({ }^{\circ} \mathrm{OH}\right)$ are directly (a)

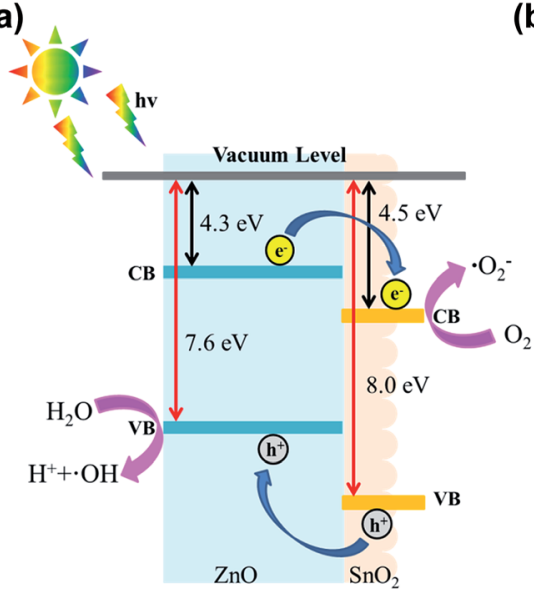

(b)

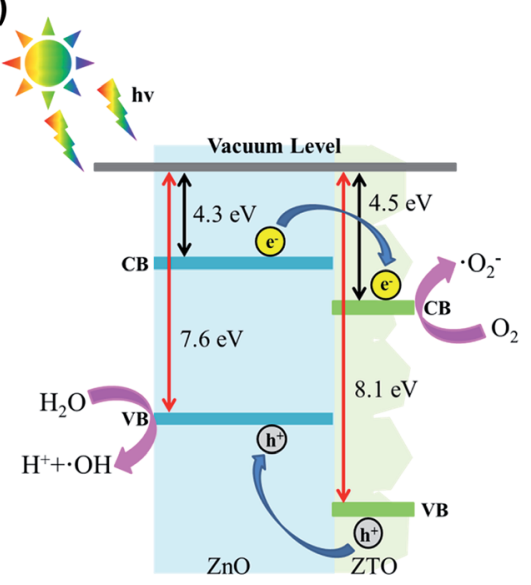

Electron affinity of $\mathrm{ZnO}=4.3 \mathrm{eV}$

$$
\begin{aligned}
& \mathrm{SnO}_{2}=4.5 \mathrm{eV} \\
& \mathrm{ZTO}=4.5 \mathrm{eV}
\end{aligned}
$$

Fig. 8 The schematics of band structure and charges transfer of the (a) $\mathrm{ZnO}-\mathrm{SnO}_{2}$ and (b) $\mathrm{ZnO}-\mathrm{ZTO}$. 
formed by the reaction of the photoexcited holes in the $\mathrm{ZnO}$ core with the adsorbed $\mathrm{H}_{2} \mathrm{O}\left(\mathrm{h}^{+}+\mathrm{H}_{2} \mathrm{O} \rightarrow \mathrm{H}^{+}+{ }^{\circ} \mathrm{OH}\right)$. The hydroxyl radical $\left({ }^{\circ} \mathrm{OH}\right)$ is an extremely strong oxidant for the mineralization of organic chemicals. ${ }^{37}$ An efficient charge separation in the $\mathrm{ZnO}-\mathrm{SnO}_{2}$ and $\mathrm{ZnO}-\mathrm{ZTO}$ heterostructures caused by a suitable band alignment between $\mathrm{ZnO}$ and $\mathrm{SnO}_{2}$ (or ZTO) decreased the recombination of the photoexcited electron-hole pairs in the composite nanorods. The increased number of free carriers in the composite nanorods substantially contributed to the higher photodegradation performance of the $\mathrm{ZnO}-\mathrm{SnO}_{2}$ and $\mathrm{ZnO}-\mathrm{ZTO}$ nanorods than that of the pure $\mathrm{ZnO}$ nanorods under irradiation. An enhanced efficiency in the interfacial charge transfer to adsorbed pollutants has been observed in the $\mathrm{SnO}_{2}-\mathrm{TiO}_{2}$ heterostructure system, which has a band alignment feature similar to that of the $\mathrm{ZnO}-\mathrm{SnO}_{2}$ and ZnO-ZTO nanorods in this work. ${ }^{38}$ Additionally, the superior photocatalytic performance of the ZnO-ZTO nanorods compared with that of the $\mathrm{ZnO}-\mathrm{SnO}_{2}$ nanorods in this study is associated with microstructural differences between the $\mathrm{ZnO}-$ $\mathrm{SnO}_{2}$ and $\mathrm{ZnO}-\mathrm{ZTO}$ nanorods. PL analysis revealed that the charge separation efficiency of the ZnO-ZTO nanorod was substantially higher than that of the $\mathrm{ZnO}-\mathrm{SnO}_{2}$ nanorod. It is posited that the surface crystal defects in semiconductors act as traps and prevent the recombination of photoexcited electrons and holes. ${ }^{39}$ In $\mathrm{WO}_{3}$ and $\mathrm{BiPO}_{4}$ oxide semiconductors, research results demonstrate that the surface oxygen vacancy of the oxides accelerates the separation of the photoinduced electronhole pairs and improves the photocatalytic properties accordingly. ${ }^{40,41}$ Moreover, the ZnO-ZTO nanorods' having a more rugged surface compared with that of the $\mathrm{ZnO}-\mathrm{SnO}_{2}$ nanorods increased multiple light scattering between the nanorods and irradiated solar light in the photodegradation tests. ${ }^{5,11}$ UV-Vis optical analysis results revealed that the ZnO-ZTO nanorod had a higher degree of light-harvesting efficiency under solar light irradiation. The literature has shown that postannealinginduced surface roughening in ZnO-CdS nanorods contributes to enhanced photocatalytic properties because of the improved light harvesting of the $\mathrm{ZnO}-\mathrm{CdS}$ composite nanorods. ${ }^{42}$ The aforementioned factors account for the superior photocatalytic activity of the ZnO-ZTO nanorods in this study.

Fig. 9(a)-(c) show the dynamic gas-sensing response curves of the $\mathrm{ZnO}, \mathrm{ZnO}-\mathrm{SnO}_{2}$, and $\mathrm{ZnO}-\mathrm{ZTO}$ nanorods to $\mathrm{NO}_{2}$ gas at various concentrations (1-10 ppm). The sensitivity of the sensors made from various nanorods to various $\mathrm{NO}_{2}$ concentrations is summarized in Fig. 9(d). Clearly, the gas-sensing sensitivity of the various sensors increased with the $\mathrm{NO}_{2}$ gas concentration; this is because higher $\mathrm{NO}_{2}$ gas concentrations caused more $\mathrm{NO}_{2}$ gas molecules to adsorb onto the surfaces of the nanorods during the gas-sensing tests. The gas-sensing sensitivities of the gas sensor comprising $\mathrm{ZnO}$ nanorods increased from 1.7 to 2.3 when the $\mathrm{NO}_{2}$ gas concentration was increased from 1 to $10 \mathrm{ppm}$. The gas-sensing sensitivities of the sensor with $\mathrm{ZnO}-\mathrm{SnO}_{2}$ nanorods were 4.4 and 9.8 on exposure to 1 and $10 \mathrm{ppm} \mathrm{NO}_{2}$ gas, respectively. At a given $\mathrm{NO}_{2}$ gas concentration, the gas-sensing sensitivities of the sensor comprising ZnO-ZTO nanorods were higher than those of the sensors made from $\mathrm{ZnO}$ and $\mathrm{ZnO}-\mathrm{SnO}_{2}$ nanorods. The response times of the sensor comprising $\mathrm{ZnO}$ nanorods were in the range of approximately 74-118 s, and the recovery times were in the range of 838-1205 $\mathrm{s}$ on exposure to 1-10 ppm of $\mathrm{NO}_{2}$ gas. Moreover, the response times of the sensor made from $\mathrm{ZnO}-$ $\mathrm{SnO}_{2}$ nanorods were in the range of approximately 62-82 s, and

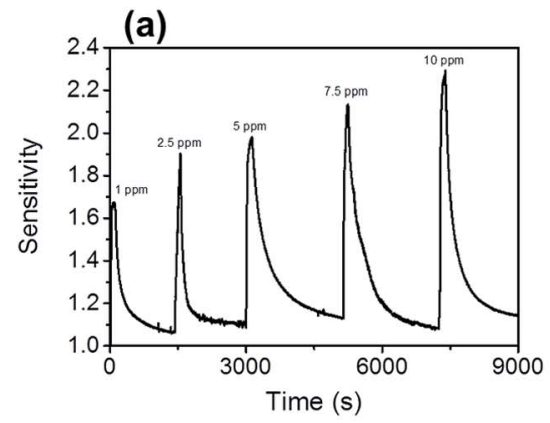

(d)

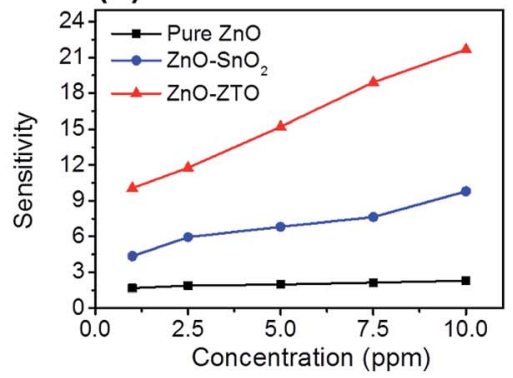

(b)

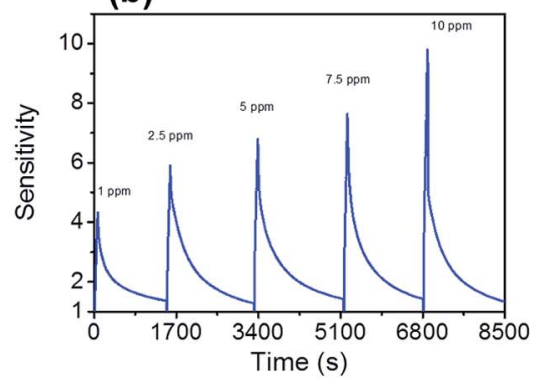

(e)

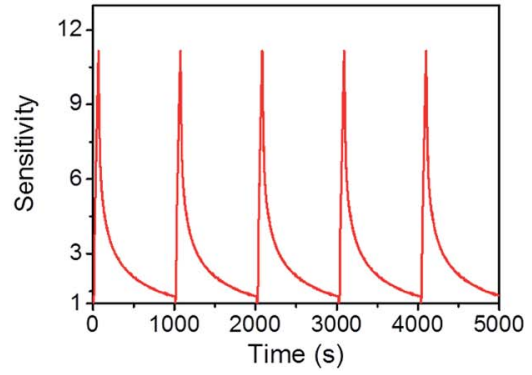

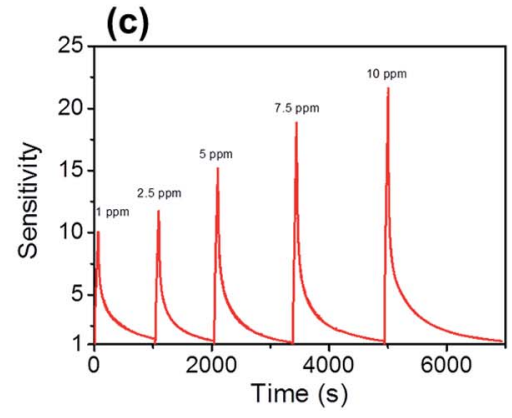$$
\text { . }
$$ 
the recovery times were in the range of 692-1069 $\mathrm{s}$ on exposure to 1-10 ppm of $\mathrm{NO}_{2}$ gas. For the sensor made from $\mathrm{ZnO}-\mathrm{ZTO}$ nanorods, the response times and recovery times on exposure to 1-10 ppm of $\mathrm{NO}_{2}$ gas were in the ranges of 56-79 s and 488$907 \mathrm{~s}$, respectively. Comparatively, the formation of $\mathrm{a} \mathrm{SnO}_{2}$ shell layer or ZTO shell layer onto the surfaces of the ZnO nanorods markedly decreased the response time and recovery time during the gas-sensing tests. The gas sensor comprising ZnO-ZTO nanorods exhibited superior $\mathrm{NO}_{2}$ gas-sensing performance in this study, achieving the highest gas-sensing sensitivity and shortest response time and recovery time on exposure to $\mathrm{NO}_{2}$ gas at a given $\mathrm{NO}_{2}$ concentration. A schematic diagram (Fig. 10(a)-(c)) was used to explain the differences in gassensing response behavior of the $\mathrm{ZnO}, \mathrm{ZnO}-\mathrm{SnO}_{2}$, and $\mathrm{ZnO}-$ ZTO nanorods. First, with respect to ZnO nanorods, the application of the $\mathrm{SnO}_{2}$ and ZTO shell layers to $\mathrm{ZnO}$ nanorods produced more active sites on the surfaces of the $\mathrm{ZnO}-\mathrm{SnO}_{2}$ and ZnO-ZTO nanorods for adsorbing $\mathrm{NO}_{2}$ gas molecules with higher efficiency (Fig. 10(b) and (c)). This is attributed to the fact that the surfaces of the $\mathrm{ZnO}-\mathrm{SnO}_{2}$ and $\mathrm{ZnO}-\mathrm{ZTO}$ nanorods are more rugged than those of pure $\mathrm{ZnO}$ nanorods, which have a smooth surface (Fig. 10(a)). Of various nanorod samples, the ZnO-ZTO nanorods exhibited the roughest surface features, as revealed from the aforementioned microstructural analyses. The surfaces of the $\mathrm{ZnO}-\mathrm{ZTO}$ are expected to provide more adsorbed sites for the $\mathrm{NO}_{2}$ gas molecules during the gas-sensing tests. The rough surface of $\mathrm{TiO}_{2}-\mathrm{WO}_{3}$ nanorods results in an increment in the number of surface-adsorbed oxygen ions, quickens the rate of the sensing reaction between reductive gases and surface-adsorbed oxygen ions, and facilitates the gas adsorption and diffusion on composite nanorods, thus leading to enhanced gas-sensing performance. ${ }^{\mathbf{4 3}}$ Moreover, oxygen vacancies, which are a commonly observed point defect in $n$ type oxides, are beneficial for the gas-sensing behavior of $n$ type semiconductor oxides. Oxygen vacancies donate electrons to the conduction band of n-type semiconductor oxides, and the existence of oxygen vacancies in nanostructured oxide surfaces increases the electrostatic interaction between the oxide surface and the reactive $\mathrm{NO}_{2}$ molecules. ${ }^{44}$ The high-temperature solidstate reaction formation of the ZTO shell of the ZnO-ZTO nanorods produced more oxygen vacancies in its surface. The ZTO surface had a higher concentration of donor-related defects and higher $\mathrm{NO}_{2}$ gas-molecule surface adsorption efficiency than did the $\mathrm{SnO}_{2}$ shell of the $\mathrm{ZnO}-\mathrm{SnO}_{2}$ and $\mathrm{ZnO}$ nanorod surfaces. In addition to the microstructural differences among the various nanorod samples, which might affect their $\mathrm{NO}_{2}$ gas-sensing performance, the band alignment between the core and shell materials plays an important role in affecting the gas-sensing performance. Notably, the work function of $\mathrm{ZnO}$ is $5.2 \mathrm{eV} ; \mathrm{SnO}_{2}$ and ZTO have a similar value of $4.9 \mathrm{eV}{ }^{\mathbf{1 5 , 4 5}}$ The work function value of $\mathrm{ZnO}$ is higher than that of $\mathrm{SnO}_{2}$ and ZTO; accordingly, when the heterostructure was formed, a thin depletion layer was expected to form in the $\mathrm{SnO}_{2}$ and ZTO shell layers and an electron accumulation layer in the $\mathrm{ZnO}$ core; ${ }^{\mathbf{4 6}}$

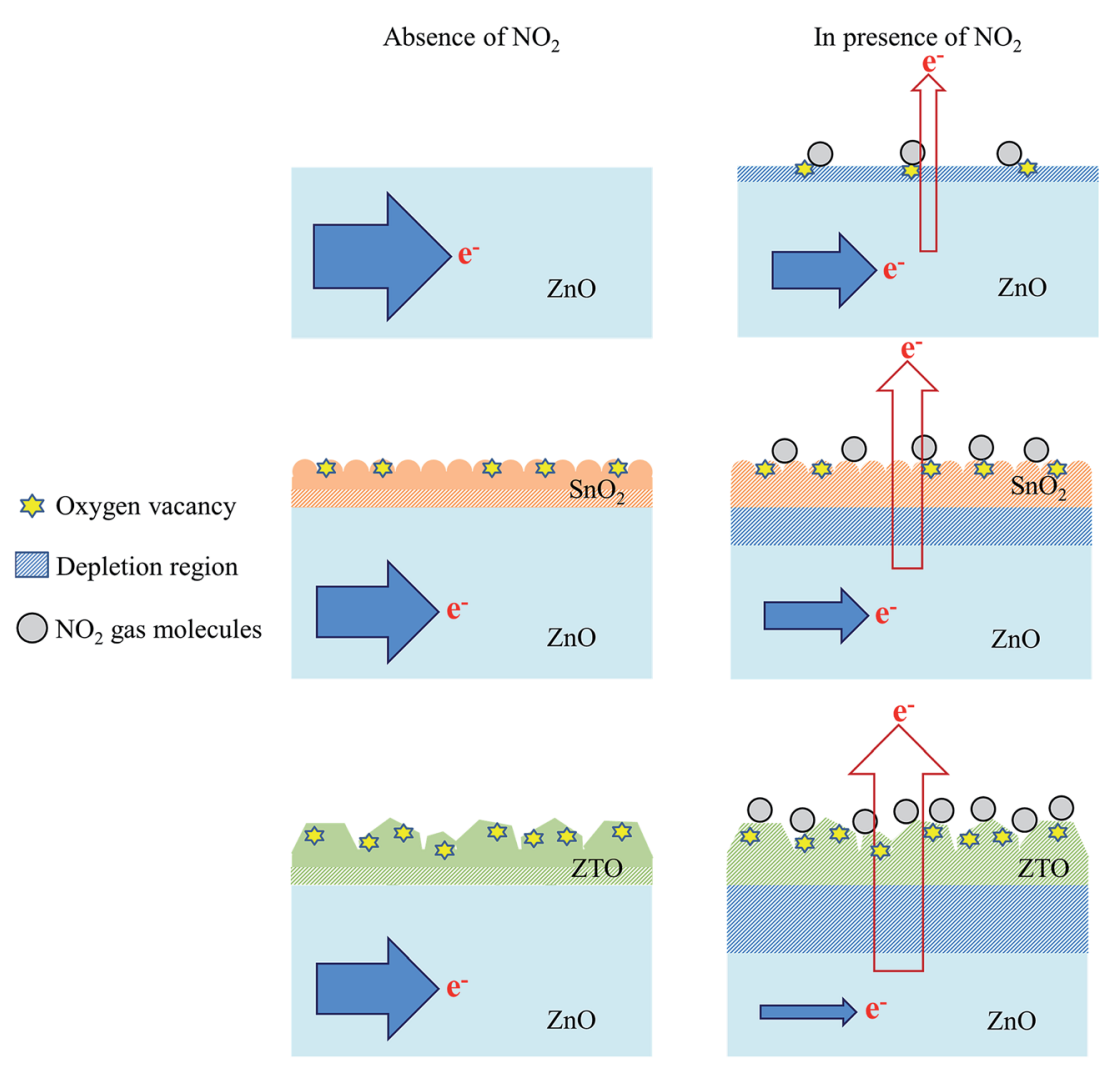

Fig. 10 The schematics of gas-sensing mechanisms for various nanorod samples on exposure to $\mathrm{NO}_{2}$ gas. The size of blue arrows presents current size. The size of red arrows represents extracted electron number. 
a marked potential barrier was formed at the heterointerface between the $\mathrm{ZnO}$ and $\mathrm{SnO}_{2}$ (or ZTO). When the $\mathrm{ZnO}-\mathrm{SnO}_{2}$ and ZnO-ZTO nanorods were exposed to $\mathrm{NO}_{2}$ gas, the adsorbed $\mathrm{NO}_{2}$ molecules extracted the surface electrons from the nanorods. Because of the microstructural differences, more $\mathrm{NO}_{2}$ molecules were expected to be adsorbed onto the surfaces of the $\mathrm{ZnO}-\mathrm{ZTO}$ nanorods at a given $\mathrm{NO}_{2}$ gas concentration during the gas-sensing tests; a relatively large degree of surface electron extraction occurred in the ZnO-ZTO system (Fig. 10(c)). Notably, the shell layer thicknesses of the $\mathrm{SnO}_{2}$ and ZTO shell layers of the composite nanorods were in the range of approximately 14$20 \mathrm{~nm}$. In general, at temperatures higher than $200{ }^{\circ} \mathrm{C}$, the surface depletion of $n$-type semiconductor oxides is in the range of tens of nanometers under a reactive gas atmosphere containing gas molecules that extract the surface electrons near the oxide surface. ${ }^{3}$ At $300{ }^{\circ} \mathrm{C}$, fully depleted $\mathrm{SnO}_{2}$ and ZTO crystallites might be observed in the shell layers during the $\mathrm{NO}_{2}$ gassensing tests. At a relatively high $\mathrm{NO}_{2}$ gas concentration, the electrons in the $\mathrm{ZnO}$ core were further released into the shell layer because increased numbers of surface adsorbed $\mathrm{NO}_{2}$ gas molecules extracted more electrons from the oxides. Because the ZnO-ZTO nanorods exhibited higher ability to adsorb $\mathrm{NO}_{2}$ gas molecules, a larger variation size of the interfacial potential barrier could occur in the ZnO-ZTO nanorods compared with that in the $\mathrm{ZnO}-\mathrm{SnO}_{2}$ nanorods at the given $\mathrm{NO}_{2}$ concentration during the gas-sensing tests. The aforementioned discussions explain the substantial improvement in the gas-sensing performance of the $\mathrm{ZnO}-\mathrm{SnO}_{2}$ nanorods through microstructure and phase modification, which was achieved in this study by conducting a high-temperature solid-state reaction procedure.

\section{Conclusions}

The $\mathrm{ZnO}-\mathrm{SnO}_{2}$ core-shell nanorods were synthesized through hydrothermal and sputtering methods. The subsequent postannealing procedure at $900{ }^{\circ} \mathrm{C}$ caused the surface crystallite size of the shell layer to become large. Moreover, crystal structure analyses revealed that the sputtering-deposited ultrathin $\mathrm{SnO}_{2}$ shell layer of the $\mathrm{ZnO}-\mathrm{SnO}_{2}$ nanorods was phase transformed into ternary ZTO when the composite nanorods were postannealed at $900{ }^{\circ} \mathrm{C}$. XPS investigations revealed that the hightemperature solid-state reaction of the $\mathrm{ZnO}-\mathrm{SnO}_{2}$ nanorods induced a substantial increase in the surface oxygen vacancy density of the ZnO-ZTO composite nanorods, and the ZnO-ZTO core-shell nanorods demonstrated a broadened optical absorbance edge, revealing a higher degree of light harvesting by the $\mathrm{ZnO}-\mathrm{ZTO}$ nanorods than the $\mathrm{ZnO}-\mathrm{SnO}_{2}$ nanorods. The differences in the microstructures and optical properties between the $\mathrm{ZnO}_{-} \mathrm{SnO}_{2}$ and $\mathrm{ZnO}-\mathrm{ZTO}$ nanorods accounted for the higher photocatalytic activity of the ZnO-ZTO nanorods than the ZnO$\mathrm{SnO}_{2}$ nanorods in this study. Moreover, modifications of the microstructure and phase of the $\mathrm{ZnO}-\mathrm{SnO}_{2}$ nanorods after a high-temperature solid-state reaction procedure substantially improved the gas-sensing sensitivity of the composite nanorods on exposure to low-concentration $\mathrm{NO}_{2}$ gases.

\section{Acknowledgements}

This work is supported by the Ministry of Science and Technology of Taiwan (Grant No. MOST 105-2628-E-019-001-MY3).

\section{References}

1 L. Xu, B. Wei, W. Liu, H. Zhang, C. Su and J. Che, Nanoscale Res. Lett., 2013, 8, 536.

2 R. Vedarajan, S. Ikeda and N. Matsumi, Nanoscale Res. Lett., 2014, 9, 573.

3 Y. C. Liang, S. L. Liu and H. Y. Hsia, Nanoscale Res. Lett., 2015, 10, 350.

4 Y. Liu, P. Yang, J. Li, K. M. Postolek, Y. Yue and B. Huang, RSC Adv., 2015, 5, 98500-98507.

5 Y. C. Liang, T. Y. Lin and C. M. Lee, CrystEngComm, 2015, 17, 7948-7955.

6 H. Silva, C. M. Pedrero, C. Magén, D. A. P. Tanaka and A. Mendes, RSC Adv., 2014, 4, 31166-31176.

7 Y. C. Liang and Y. R. Cheng, CrystEngComm, 2015, 17, 58015807.

8 B. Weng, S. Liu, Z. R. Tang and Y. J. Xu, RSC Adv., 2014, 4, 12685-12700.

9 S. W. Choi, A. Katoch, G. J. Sun, J. H. Kim, S. H. Kim and S. S. Kim, ACS Appl. Mater. Interfaces, 2014, 6, 8281-8287.

10 A. Katoch, S. W. Choi, G. J. Sun and S. S. Kim, J. Mater. Chem. A, 2013, 1, 13588-13596.

11 Y. C. Liang and C. M. Lee, J. Appl. Phys., 2016, 120, 135306.

12 Y. C. Liang, C. M. Lee and Y. J. Lo, RSC Adv., 2017, 7, 47244734 .

13 Y. F. Wang, Y. Ding, J. S. Zhao, X. Wang, D. J. Li and X. F. Li, RSC Adv., 2016, 6, 69191-69195.

14 G. Ma, R. Zou, L. Jiang, Z. Zhang, Y. Xue, L. Yu, G. Song, W. Li and J. Hu, CrystEngComm, 2012, 14, 2172-2179.

15 Z. Zhang, C. Shao, X. Li, L. Zhang, H. Xue, C. Wang and Y. Liu, J. Phys. Chem. C, 2010, 114, 7920-7925.

16 B. Cheng, J. Xu, Z. Ouyang, X. Su, Y. Xiao and S. Lei, J. Mater. Chem. C, 2014, 2, 1808-1814.

17 Y. C. Liang, W. K. Liao and S. L. Liu, $R S C A d v ., 2014,4$, 50866-50872.

18 Y. C. Liang, C. Y. Hu and Y. C. Liang, CrystEngComm, 2012, 14, 5579-5584.

19 Y. C. Liang and W. K. Liao, RSC Adv., 2014, 4, $19482-19487$. 20 H. W. Kim, J. W. Lee, M. A. Kebede, H. S. Kim and C. Lee, Mater. Sci. Eng., B, 2009, 163, 44-47.

21 Y. F. Tu, Q. M. Fu, J. P. Sang, Z. J. Tan and X. W. Zou, Mater. Lett., 2012, 86, 80-83.

22 Y. C. Liang and T. Y. Lin, Nanoscale Res. Lett., 2014, 9, 344350.

23 Y. C. Liang, C. Y. Hu, H. Zhong and J. L. Wang, Nanoscale, 2013, 5, 2346-2351.

24 J. Wang, W. Zhou and P. Wu, Appl. Surf. Sci., 2014, 314, 188192.

25 Y. C. Liang, M. Y. Tsai, C. L. Huang, C. Y. Hu and C. S. Hwang, J. Alloys Compd., 2011, 509, 3559-3565.

26 Y. C. Liang and X. S. Deng, J. Alloys Compd., 2013, 569, 144149. 
27 M. Ebadi, Z. Zarghami and K. Motevalli, Phys. E, 2017, 87, 199-204.

28 Y. C. Liang and Y. C. Liang, Appl. Phys. A: Mater. Sci. Process., 2009, 97, 249-255.

29 S. Duo, Y. Li, Z. Liu, R. Zhong, T. Liu and H. Xu, J. Alloys Compd., 2017, 695, 2563-2579.

30 A. Farhadi, M. R. Mohammadi and M. Ghorbani, J. Photochem. Photobiol., A, 2017, 338, 171-177.

31 S. A. Ansari, M. M. Khan, S. Kalathil, A. Nisar, J. Lee and M. H. Cho, Nanoscale, 2013, 5, 9238-9246.

32 J. Wang, Z. Wang, B. Huang, Y. Ma, Y. Liu, X. Qin, X. Zhang and Y. Dai, ACS Appl. Mater. Interfaces, 2012, 4, 4024-4030.

33 M. Kwiatkowski, R. Chassagnon, O. Heintz, N. Geoffroy, M. Skompska and I. Bezverkhyy, Appl. Catal., B, 2017, 204, 200-208.

34 Y. C. Liang and W. K. Liao, Appl. Surf. Sci., 2014, 292, 632637.

35 R. Liu, Y. Huang, A. Xiao and H. Liu, J. Alloys Compd., 2010, 503, 103-110.

36 M. Zhang, T. An, X. Hu, C. Wang, G. Sheng and J. Fu, Appl. Catal., A, 2004, 260, 215-222.
37 F. Kiriakidou, D. I. Kondarides and X. E. Verykios, Catal. Today, 1999, 54, 119-130.

38 H. Shi, M. Zhou, D. Song, X. Pan, J. Fu, J. Zhou, S. Ma and T. Wang, Ceram. Int., 2014, 40, 10383-10393.

39 Y. Li, C. Wang, H. Zheng, F. Wan, F. Yu, X. Zhang and Y. Liu, Appl. Surf. Sci., 2017, 391, 654-661.

40 Y. Li, Z. Tang, J. Zhang and Z. Zhang, J. Alloys Compd., 2017, 708, 358-366.

41 Y. Lv, Y. Liu, Y. Zhu and Y. Zhu, J. Mater. Chem. A, 2014, 2, 1174-1182.

42 Y. C. Liang, C. C. Chung, Y. J. Lo and C. C. Wang, Materials, 2016, 9, 1014.

43 H. Zhang, S. Wang, Y. Wang, J. Yang, X. Gao and L. Wang, Phys. Chem. Chem. Phys., 2014, 16, 10830-10836.

44 M. W. Ahn, K. S. Park, J. H. Heo, J. G. Park, D. W. Kim, K. J. Choi, J. H. Lee and S. H. Hong, Appl. Phys. Lett., 2008, 93, 263103.

45 C. Pang, B. Yan, L. Liao, B. Liu, Z. Zheng, T. Wu, H. Sun and T. Yu, Nanotechnology, 2010, 21, 465706.

46 Y. C. Liang and S. L. Liu, Acta Mater., 2015, 88, 245-251. 